http://dx.doi.org/10.18232/alhe.1015

Artigos

\title{
Negociantes e capitalistas: transformações das práticas mercantis no Brasil imperial, em meados do século XIX, Ouro Preto, Minas Gerais
}

\section{Traders and Capitalists: Transformation of Commercial Practices in Brazil Imperial in Nineteen Century Mid, Ouro Preto, Minas Gerais}

Leandro B. de Andrade ${ }^{1, *}$ * (D000-0002-0666-2158

${ }^{1}$ Centro Federal de Educação Tecnológica de Minas Gerais, Minas Gerais, Brasil.

* Correspondencia: leandrohist.andrade@gmail.com

Resumo. O estudo analisa alguns elementos das práticas de mercado, em transformação durante o século xIX, principalmente os instrumentos do ofício dos comerciantes, as formas de investimentos e as instituições financeiras. O foco são os agentes mercantis de Ouro Preto, capital da província de Minas Gerais, onde as possiblidades de acumulação eram restritas por sua posição periférica no mercado interno brasileiro. $\mathrm{O}$ objetivo é demonstrar, no entanto, que o caráter urbano do comércio e da riqueza dessa região acompanhava o processo de modernização e institucionalização pelo qual passava a economia e o Estado nacional. Dessa forma, a abordagem microanalítica mostrou-se eficaz ao revelar quando tais transformações ocorreram e como foram ativadas pelos negociantes e capitalistas locais.

Palavras-chave: práticas mercantis; comércio urbano; investimentos; capitalistas.

CÓMO CITAR: Andrade, L. B. (2020). Negociantes e capitalistas: transformações das práticas mercantis no brasil imperial, em meados do século XIX, Ouro Preto, Minas Gerais. América Latina en la Historia Económica, 27(1), e1015. DOI: 10.18232/alhe.1015 
Abstract. The study examines some of the practical elements of market transformation during the nineteenth century especially the tools of the trade of merchants, forms of investment and financial institutions. The focus is on commercial agents of Ouro Preto, capital of the province of Minas Gerais, where the possibilities of accumulation were restricted by their peripheral position in the Brazilian market. The objective is to demonstrate, however, that the urban character of trade and wealth of the region accompanied the process of modernization and institutionalization through which passed the economy and the national state. Thus, the micro analytic approach was effective in revealing when such changes occurred and how local merchants and capitalists activated them.

Key words: commercial practices; urban trade; investments; capitalists.

JEL: F54

Recebido: 17 de agosto de 2018.

Aceito: 6 de novembro de 2018.

Publicado: 18 de setembro de 2019.

\section{INTRODUÇÃO}

O processo de modernização das relações comerciais e de transformação das práticas de mercado, no passo do desenvolvimento do capitalismo, ocorreu de forma lenta e variada no território do Brasil. Confunde-se com a complicada busca por estabilidade política e institucional do próprio Estado Nacional, diante de uma configuração bastante heterogênea de interesses, de grupos sociais e de realidades regionais.

No período da independência, o Brasil se inseria nas relações econômicas internacionais, correlacionando sua condição de exportador primário escravista com a criação e consolidação de suas instituições políticas e suas leis, com a diversidade de seu território e o desenvolvimento das trocas internas. Essas condições específicas fizeram com que a estrutura escravista mercantil dos tempos coloniais sobrevivesse e convivesse com a aceleração das trocas e consequente desenvolvimento de novas práticas mercantis no espaço interno.

Os principais vetores da economia eram as produções agroexportadoras, o setor monopolizador da importação, exportação e circulação interna de mercadorias e o grande comércio, integrado com um incipiente setor financeiro. A expansão da economia nacional, puxada por esse nível superior da engrenagem econômica e sentida nas produções abastecedoras e nos mercados urbanos, tornava as transações do mercado mais complexas, o que aumentava as necessidades de regulamentação, profissionalização e institucionalização.

Para Pelaez e Suzigan (1981, p. 68), na década de 1830, iniciava-se o processo que consolidaria o modelo de desenvolvimento econômico e financeiro do Brasil. Cresciam as exportações, passando a serem lideradas pelo café, consolidava-se a dependência da mão-de-obra escrava e parcela significativa dos lucros concentrava-se nas mãos dos agentes urbanos do mercado. No mesmo período, emergia uma nova elite política, representante dos interesses de setores produtivos diversos e altamente mercantilizados.

A necessidade de ampliação de crédito, percebida pelas praças comerciais, fez surgirem bancos comerciais nos principais centros portuários do país, nas décadas de 1830 e 1840: Rio de Janeiro, Bahia, Pernambuco, Rio Grande do Sul e Pará. As instituições bancárias foram, então, as primeiras grandes empresas por associação de capitais, as sociedades anônimas, nas quais o ca- 
pital é distribuído em ações comercializáveis e a instituição é dirigida por um mandatário, sócio ou não (Levy, 1994). O controle do crédito, no entanto, continuaria nas mãos de grandes e tradicionais negociantes usurários, na prática, alguns dos sócios dos novos bancos e intermediário dos empréstimos ao setor produtivo (Guimarães, 1997).

O final da década de 1840 foi um período de importantes inflexões na legislação e regulação econômica no Brasil. Bárbara Levy (1994, p. 46) considera este, o início de uma série de medidas institucionais que "contribuíram para a integração do país no processo de acumulação e delineamento do capitalismo interno”. As principais medidas foram: a tarifa Alves Branco de 1844, que aumentou a taxação de manufaturados importados, a adoção do Padrão Ouro em 1846; a lei das Sociedades Anônimas de 1849; a Lei de Terras de 1850, que restringiu o acesso à terra, criando um mercado para o setor, a Lei Euzébio de Queiroz, de 1850, que abolição o tráfico de escravos, disponibilizando recursos para a economia, e, por fim, o Código Comercial Brasileiro, também de 1850 .

Todas essas mudanças, obviamente, estão inscritas na consolidação e centralização do Estado Imperial, ocorridas no Segundo Reinado, não apenas pela regulamentação do funcionamento da economia e da sociedade, mas são também resultados de disputas e interesses de grupos sociais. Para Carlos Gabriel Guimarães (1997), o novo conjunto de medidas outorgava ao Estado a condição de mediador-catalisador institucional dos interesses dos grupos sociais dominantes, a saber, os grandes negociantes e proprietários de terras e escravos. Seguindo as teses de Ilmar Mattos (1990), para o qual a elite política conservadora do Rio de Janeiro teria comandado esse processo, conciliando a estabilidade política com os privilégios à sua base social, Guimarães (2012) defende que as novas práticas empresariais não estavam dissociadas de fatores sociais e políticos, como a organização familiar e o trânsito nos centros de poder.

A Lei de Terras (1850), por exemplo, nos dizeres de Bárbara Levy (1994), ao legitimar as ocupações desregradas de terras ocorridas antes da legislação, "congelava a hierarquia social do Império” (p. 48), pautada no latifúndio. Já a aprovação do Código Comercial, segundo Roberto Saba (2010), teve uma participação fundamental dos grandes negociantes das cidades mais ricas do império. Eles reclamavam da inexistência de uma justiça mercantil específica, de regulamentação que evitasse falências fraudulentas e da falta de uma resposta legal efetiva aos maus devedores. A ação dos comerciantes grossistas manifestava-se em cartas e petições que expressavam o desejo de maior segurança na atividade creditícia.

A aprovação do Código Comercial, em 25 de junho de 1850, foi o marco mais significativo no intuito de promover segurança, estimular e consolidar a diversificação das práticas mercantis mais sofisticadas, com a movimentação das maiores somas de capital. Portanto, apesar de regulamentar todos os setores do comércio, atendia no curto prazo, às demandas do topo da pirâmide da hierarquia mercantil. Um decreto publicado meses depois definia quais os setores incluídos no escopo regulamentador do Código:

Artigo 19. Considera-se mercancia: SS $1^{\circ}$. A compra e venda ou troca de efeitos moveis ou semoventes, para os vender por grosso ou a retalho, na mesma especie ou manufacturados, ou para alugar o seu uso. SS $2^{\circ}$. As operações de cambio, banco e corretagem. SS $3^{\circ}$. As emprezas de fabricas, de commissões de deposito; de expedição, consignação e transporte de mercadoria; de espectaculos públicos $\mathrm{SS} 4^{\circ}$. Os seguros, fretamento, risco, e quaisquer contratos relativos ao commerciomaritimo. SS $5^{\circ}$. A armação e expedição de navios (Brasil, 1909, p. 76, in Guimarães, 2012, p. 92). 
A inclusão das operações bancárias, seguros, corretagem e de fábricas na definição da mercancia é uma clara reação ao próprio desenvolvimento do mercado, pois, mesmo sem a devida regulamentação, esses setores já funcionavam e se multiplicavam no Brasil.

Estamos denominando como desenvolvimento do mercado, o resultado contínuo de aceleração, intensificação e crescimento das trocas. A orientação mercantil passa a responder cada vez mais pela cobertura das necessidades, diante do crescimento demográfico, urbanização, integração econômico-espacial, eficiência na busca pelo lucro e aumento da produtividade, tanto das unidades de produção familiares ou escravistas.

A modernização das formas de acumulação, em uma sociedade ainda pré-industrial, obedece, como orienta Fernand Braudel (1996), os caminhos trilhados pelo setor mercantil. Estes produzem um efeito em cascata, desde os centros comerciais-financeiros e capitalistas mais ricos até as instâncias inferiores do mercado.

Nesse sentido, a multiplicação das sociedades comerciais, sociedades de capitais e investimentos financeiros, no Rio de Janeiro, eram sinais dos novos tempos. Apesar da timidez industrial e da manutenção da escravidão, há um empresariado com características diferentes, controlando os bancos, as seguradoras e o crédito (Fragoso e Martins, 2003).

Da capital do império e de outras grandes praças comerciais, como Salvador, Recife e São Paulo, essas novas práticas chegavam ao interior, sobretudo nos meios urbanos. Interessa-nos verificar, como este conjunto de transformações incidem sobre os instrumentos, investimentos e práticas de mercado.

A "Imperial Cidade de Ouro Preto", apesar de capital de Minas Gerais, era um centro comercial de dimensão regional, em torno do qual gravitavam alguns distritos e municípios da área central da província. A grande extensão territorial e a multiplicação de pequenos e médios centros urbanos desconcentravam a atividade mercantil em Minas Gerais, que quase absolutamente se reportava ao Rio de Janeiro, como referência para exportação e importação.

Rodarte, Paula e Simões (2004) desenvolveram minuciosa pesquisa acerca da urbanização na província de Minas Gerais, na década de 1830, na qual identificou a capital Ouro Preto com o mais alto nível de centralidade urbana (nível 1), juntamente com Serro. A centralidade urbana, conforme trabalhada pelos autores, é uma categoria que se refere ao grau de existência de serviços públicos, atividades manufatureiras, mercantis e profissionais liberais.

Na capital provincial, como em outras cidades importantes, havia uma pequena, mas poderosa elite de negociantes que controlava o grande comércio local, intermediando mercadorias, crédito e práticas de negócios entre o Rio de Janeiro e o interior. Esse grupo destacou-se no comércio de manufaturados importados, escravos, animais e, principalmente, emprestando dinheiro a juros para produtores, para pequenos comerciantes e para a população em geral. Aqueles com maior poderio financeiro e melhor inserção política conseguiram se tornar intermediários das companhias de mineração inglesa que se instalaram na região desde a década de 1820, fazendo renascer a extração aurífera, a qual, a partir de então, tornou-se subterrânea e recebeu vultosos investimentos (Andrade, 2013).

A partir da análise das escrituras cartoriais de Ouro Preto foi possível flagrar o destaque dos comerciantes em diversos setores de transações: comércio de imóveis, comércio de escravos e, principalmente, nas escrituras de dívida e hipoteca. Em que pese a relativa dispersão do crédito pessoal, uma característica das economias pré-industriais e pré-bancárias, um pouco mais de 50\% das transações e valores informavam comerciantes como credores, de um total de 507 escrituras 
MAPA 1. NÍVEIS DE GENTRALIDADE URBANA, MINAS GERAIS, 1831-1840

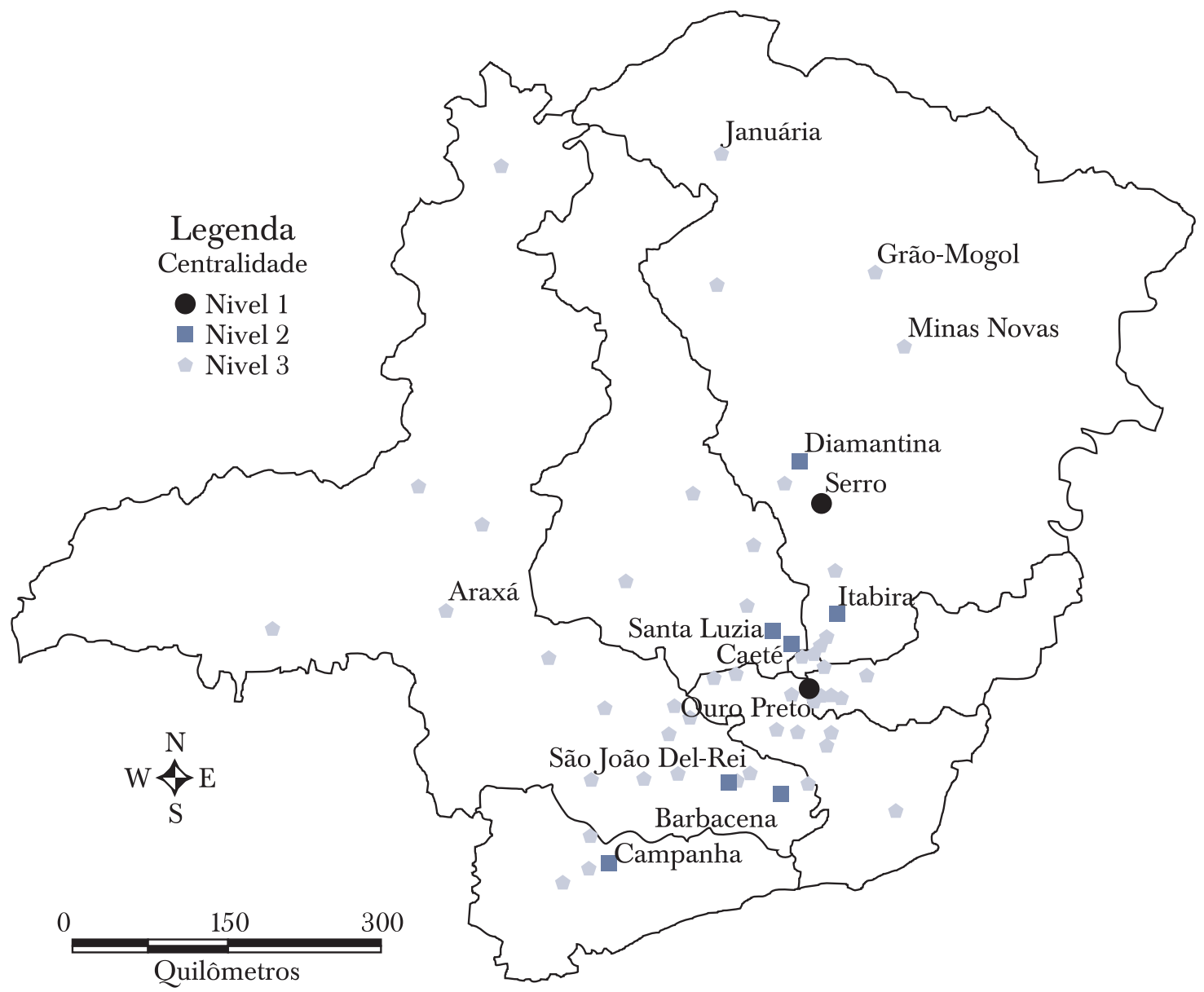

Fonte: Rodarte (2004, p. 14).

de dívida e hipoteca ${ }^{1}$ Entre 1820 e 1865 , essa concentração foi se tornando ainda maior, demonstrando a consolidação e auge da elite mercantil, principalmente entre as décadas de 1830 e 1850.

Apesar de a extração do ouro ser quase toda controlada pelo capital estrangeiro, a região de Ouro Preto não dispunha de um produto massivamente comercializado com outras regiões ou com o exterior. Esse cenário fazia com que a capital da província perdesse importância econômica e fosse notadamente mais pobre que outros centros urbanos, como São João del Rei. No entanto, sua característica marcadamente urbana, seu papel de centro administrativo e político e sua relação de reciprocidade comercial com o Rio de Janeiro fez com que práticas modernas de mercado aparecessem entre as escolhas dos mais importantes negociantes-capitalistas da cidade.

Entretanto, tais novidades conviveram e se misturaram às tradicionais formas de investir, organizar negócios ou conquistar privilégios diante da estrutura do Estado.

\footnotetext{
${ }^{1}$ Em tese de doutoramento, de onde partiram as principais reflexões deste texto, analisei uma amostra de 1535 escrituras das mais variadas naturezas, das quais 507 de dívida e hipoteca. Ver Andrade (2013, p. 184).
} 
Por meio do movimento dos negócios dos agentes mercantis é possível perceber os momentos em que ocorrem transições de práticas, instrumentos e investimentos mercantis. O objetivo não é traçar uma linha evolutiva linear do capitalismo, mas flagrar os processos e mudanças que, aos poucos, manifestavam-se no ofício dos negociantes ou nos investimentos daqueles que dispunham de capital. Dessa forma, partindo de uma análise microfocal, analisamos casos e sujeitos de um centro econômico periférico (Ouro Preto) para perceber como suas ações manifestam o processo de modernização global. ${ }^{2}$

Nesse sentido, interessa-nos mais a qualidade das informações contidas em contratos, escrituras, inventários post-mortem e em relatórios governamentais, do que o volume de dados. A análise que segue é uma experiência de rastreamento das práticas dos agentes mercantis, em meados do século XIX, em Ouro Preto, mediante a análise das sociedades comerciais, investimentos em títulos financeiros e instituições bancárias.

As SOCIEDADES COMERCIAIS E OS INSTRUMENTOS DA PRÁTICA MERCANTIL

Muitas eram as formas de associações consideradas mercantis, mas a definição básica de sociedade passava pela contribuição de mais de um interessado com alguma quota no negócio comercial. Essas participações envolviam o emprego de capital, produtos ou mesmo de trabalho. Até o século XIX, eram comuns negócios associativos serem celebrados por meio de simples correspondências ou mandatos (procurações). Agentes mercantis que atuavam nas praças portuárias ou no interior do Brasil, durante o período colonial, muitas vezes associavam-se aos grandes negociantes de Lisboa, ou mesmo aos mercadores e homens de negócios estabelecidos no litoral (Pedreira, 1995).

Para o estabelecimento de sociedades mais duráveis, com somas de capital mais elevadas ou aqueles pequenos negócios que necessitassem de maiores formalidades eram usados os contratos comerciais. Esse instrumento de formalização apresentava regras e condições mais claras do negócio específico, dando mais segurança aos sócios. Com um contrato, público ou particular, poderia se estabelecer a formação de uma firma, nome social sob o qual responderia a sociedade entre pessoas, ou uma sociedade anônima (ou companhia), sem firma, regida pela associação de capitais.

Até as primeiras décadas do século XIX, no espaço mercantil interno, mesmo havendo diversos tipos de contratos celebrados para negócios de duração curta, como para o transporte de mercadorias, eram pouco comuns sociedades que estabelecessem firmas ou companhias de capitais. Mesmo grandes negociantes e usurários, continuavam estabelecidos com casa de negócio individual. No Rio de Janeiro, por exemplo, o negócio de grosso trato ou tráfico de escravos era dominado por negociantes individuais. Na segunda década do século, no entanto, algumas empresas dedicadas ao seguro de viagens transoceânicas, negócio que exigia vultosas somas de capital, já se formalizavam como firmas ou sociedades anônimas (Fragoso, 1992).

No período joanino, esse lento movimento de formalização-institucionalização das práticas mercantis passara a ser incentivado pelo Estado, com a matrícula na Real Junta do Comércio ou mesmo a obrigatoriedade das Aulas do Comércio, criadas no Rio de Janeiro, Salvador e Recife (Chaves, 2006, p. 29). Isso revela, portanto, que as necessidades impostas pelo desenvolvimento e alargamento das trocas, disseminava instrumentos e práticas na comunidade mercantil, mas também refletia e era influenciado pela presença do Estado, pelos costumes e relações sociais. Apesar

\footnotetext{
${ }^{2}$ Sobre a abordagem microanalítica, que privilegia ação de sujeitos e grupos como forma de entender as transformações mais amplas, ver Revel (1998).
} 
da maioria dos registros na Junta do Comércio ter sido feito por negociantes de praças litorâneas, os grandes negociantes de Ouro Preto também procuraram esse instrumento de formalização, comprovando sua condição de comerciante grossista (Andrade, 2013, p. 231).

A maior parte das organizações comerciais ainda continuava, e ainda continuaria por muito tempo, sendo associações de pessoas e não de capitais. Sobre as grandes firmas mercantis em Portugal, Jorge Pedreira também acentua que "Estas associações [entre negociantes] não estavam ainda em condições de produzir uma mecanização ou despersonalização do negócio, isto é, uma institucionalização pela qual a empresa se separasse do empresário" (Pedreira, 1995, p. 398). Tanto os grandes negócios atacadistas da Corte, quanto os negócios locais do interior do Brasil, dedicados ou não à oferta de crédito, ainda permaneciam ligadas à figura do proprietário, um negociante individual ou então sob firmas mercantis que agrupavam dois ou três comerciantes.

Diante do crescimento do volume e raio de alcance das trocas no mercado interno, por exemplo, negociantes atacadistas do Rio de Janeiro se associavam para estender a capacidade de investimento e clientela. Ao mesmo tempo, é também na Corte que se multiplicava a formalização dos negócios.

Alguns exemplos pudemos encontrar na análise da documentação da loja de fazendas secas da família Machado de Magalhães, em Ouro Preto, em 1932. Das 24 fornecedoras, 16 eram firmas mercantis por associação, estabelecidas no Rio de Janeiro, como a João Gonçalves Pereira \& Cia., Duarte \& Vellozo, P. Sunderland \& Filho, entre outras. Apenas oito fornecedores eram negociantes individuais 3 Na mesma década, as firmas ou sociedades eram raríssimas em Ouro Preto, como revelado nas Relações de Casas de Negócio de 1836, quando nenhum estabelecimento se apresentou como tal. 4

Até o final da década de 1840, apenas no topo da hierarquia mercantil a prática associativa era recorrente. O poderoso negociante grossista Francisco de Paula Santos, por exemplo, mantinha, além de sua casa comercial na cidade, uma sociedade no Rio de Janeiro, a Pena Santos \& Cia. Essa firma fornecia mercadorias secas, crédito e intermediava os interesses dos comerciantes locais na Corte. Já a Guimarães Lagoa \& Cia., importadora de líquidos, era fruto da sociedade entre o negociante local Silvério Pereira da Silva Lagoa com outra casa do Rio de Janeiro, também funcionando com o objetivo de controlar o atacado de alimentos e bebidas importadas em Ouro Preto. As escrituras de dívida e hipoteca revelaram um grande montante em negócios realizados por essas duas firmas na cidade 5

Em meados do século xIx, os contratos de sociedades relativos aos estabelecimentos comerciais, principalmente as lojas, foram se popularizando, proporcionando também uma maior organização financeira, divisão de tarefas, efetiva escrituração e segurança nos negócios, sejam os familiares ou não. É importante observar como esses instrumentos chegaram ao comércio fixo de Ouro Preto, como praça mercantil interiorana, ou seja, distante do órgão de registro oficial, a Junta do Comércio (depois de 1850, Tribunal do Comércio,) e com dimensões modestas de seus estabelecimentos.

\footnotetext{
${ }^{3}$ Modesto Antônio de Magalhães, Contas e recibos, diversas datas, Acervo do Barão de Camargos, Arquivo Histórico do Museu da Inconfidência (AHMI).

${ }^{4}$ Livro de receitas e despesas, Licenças para casas de negócio, Câmara Municipal de Ouro Preto, 3-4, Arquivo Público Mineiro (APM).

${ }^{5}$ A descrição das dívidas das quais essas firmas eram credoras, em seu conjunto, nos informaram sobre sua forma de atuação e seu predomínio no mercado local. Livros de notas, livros 183-215, diversos anos, AHMI.
} 
Nas décadas de 1830 e 1840, somente três registros de contratos foram encontrados em todas escrituras cartoriais rastreadas. Alguns poucos exemplos dizem respeito a uma busca de diversificação ou expansão da atuação mercantil, não exatamente sobre o negócio principal dos negociantes envolvidos. Já a partir de 1850 , até 1865 , foram escrituradas catorze sociedades, todas dizendo respeito ao estabelecimento de loja de fazendas ou molhados para comércio varejista. Esse movimento reflete o aumento da formalização de transações mercantis, a disseminação pelo interior do Brasil da prática associativa e, também, a influência do Código Comercial (1850), que havia sistematizado condições, formalidades e regras, servindo de guia para pequenos e grandes comerciantes.

O Código comercial, em 1850, apresentava os principais tipos de sociedades, seguindo as legislações anteriores, manuais mercantis e as práticas de comércio. Seriam elas: a) sociedade em comandita, quando um ou mais sócios proprietários entravam com todo ou parte do capital, deixando a responsabilidade de administração para outros sócios; $b$ ) sociedade em nome coletivo, quando os sócios entram com capital na abertura de uma firma e dividem a responsabilidade. Era o tipo sociedade mais comum: c) sociedade capital e indústria [trabalho], quando um ou mais sócios entram com os fundos necessários e a outra parte entra somente com o trabalho. Comuns nos contratos em que um caixeiro ou gerente tem partes nos lucros; $d$ ) sociedade em conta de participação, quando os sócios se reúnem sem firma social para lucro comum, respondendo pelo nome individual de cada um ou alguns, mas com um fim social; e) sociedade anônima ou companhia, reunião de capitais de sócios anônimos em um empreendimento administrado por mandatários, sócios ou não. A legislação de 1850 exigia autorização do governo dos estatutos. Comuns no setor bancário, seguros, transporte e indústria (Codigo commercial do imperio do Brasil, 1850).

A divulgação de uma casa comercial, publicada no jornal $O$ conciliador, em julho de 1851, anunciava a chegada de "uma porção do novo código do comércio". Certamente, o dono do estabelecimento divulgado entendia que a compra do código era de interesse do público, principalmente dos comerciantes locais (Godoy, 2004, p. 398).

A sociedade de loja aberta por Fernando Luís Machado de Magalhães e seus filhos, Modesto Antônio e Antônio Luís tratava-se de uma sociedade de tipo capital e trabalho, pois, o pai entrava com todo o capital, doze contos de réis (12 000 000), e a loja seria administrada pelos filhos sócios, "debaixo da gerência do pai". Chama atenção o cuidado previsto em contrato, com a escrituração detalhada, separada por livros com funções diferentes e com a definição clara da separação entre as finanças da loja e negócios pessoais ${ }^{6}$

Na prática corriqueira, registravam-se apenas os deveres e haveres, ou seja, o fiado do balcão, créditos e o que se devia. Esse método era chamado de entradas simples. No entanto, nos manuais mercantis e nas aulas do comércio, o método de entradas duplas ou partidas dobradas era ensinado como forma contabilística mais eficiente. Consistia no registro separado da entrada e saída de mercadorias, do fiado e dos deveres, por compras ou despesas, sendo essas anotações transcritas no livro diário, um resumo contabilístico que permite o cálculo da lucratividade ou perda do capital empregado, além do valor de cada mercadoria estocada para balanços rápidos e precisos.7

\footnotetext{
${ }^{6}$ Contrato de sociedade e casa de negócio feito entre Fernando Luís Machado de Magalhães e seus filhos Modesto Antonio Machado de Magalhães e Antonio Luis de Magalhães Mosqueira. 2 de agosto de 1832. Acervo Barão de Camargos. AHMI.

${ }^{7}$ Sobre a circulação de manuais mercantis ver Chaves (2006) e Pedreira (1995) e sobre as lições desses manuais, ver Carvalho (1888).
} 
No debate sobre o desenvolvimento do capitalismo, a contabilidade racional ou contabilidade científica aparece como um dos elementos que propiciaram o alcance de lucros reais por negociantes do ocidente. E essa busca individual por ganhos, mais apurada, segundo Weber, os distinguiria na formação do capitalismo moderno (Weber, 1985). Discordando dessa proposição, B. S. Yamey argumenta que, embora as partidas dobradas fossem do conhecimento da comunidade mercantil e sugeridas por manuais, no século XVIII e primeiras décadas do século XIX, elas não eram plenamente praticadas, o que, no entanto, não impediu o desenvolvimento do capitalismo. Segundo o autor, o uso das entradas simples servia ao objetivo dos negociantes (Yamey, 1949).

Voltando ao contrato da loja dos Machado de Magalhães, é possível verificar uma tentativa de sofisticação da escrituração que traz alguns elementos do método das partidas dobradas. O primeiro livro serviria para o registro de todas as mercadorias compradas, "para em pronto se conhecer o quanto se tem empregado". O segundo livro, o borrador, se registraria o fiado, informações que seriam transpostas mensalmente ao livro diário. O terceiro seria para as despesas, de modo que os deveres fossem conhecidos. O contrato ainda previa a realização de balanços anuais, "para se conhecer quais os lucros que houverem e o que toca a cada um dos sócios" 8

Tal prática ainda era incomum em Ouro Preto, onde a existência de simples livros de assentos predominava nos negócios. No entanto, depois de 1850, foram mais comuns os indícios de modernização da contabilidade, com referências específicas aos tipos de livros ou mesmo com a menção da existência de "livros necessários para regular escrituração" e de balanços comerciais, usando, inclusive, as palavras do texto do Código Comercial.

Na sociedade comercial entre José Basílio da Gama Vilas Boas e José Luís Esteves Pereira, contratou-se, em 1854, a abertura de loja para compra e venda de fazendas secas e molhados, na qual o primeiro seria o sócio proprietário e o segundo o sócio administrador, definindo-se uma sociedade de capital e trabalho. O contrato previa exatamente a existência de livros tidos como obrigatórios pelo Código Comercial: o diário, em que se registrariam as vendas do fiado e a dinheiro, e o copiador de cartas, em que se deveriam registrar as correspondências emitidas com contas, faturas, pedidos, cobranças e instruções. Além dos obrigatórios, previu-se também o livro conta corrente, no qual se lançaria "o que se tem a receber e o que se tem a despender" de cada um dos devedores e credores. O balanço anual, que também estava previsto no código, figurava entre as cláusulas do contrato9 9

Negociantes individuais também seguiam algumas das instruções para a escrituração mercantil. No processo de falência de Jacintho da Silva Lessa, por exemplo, apresentaram-se os livros da casa comercial, a saber, um borrador, três livros diários, três de conta corrente e um de despesas. O Código Comercial exigia a numeração, selagem e rubrica de todas as páginas dos livros pela autoridade mercantil ou pela primeira autoridade judiciária nas praças onde não houvesse tribunais do comércio. Os avaliadores do negócio falido em questão atestaram, no entanto, que tal procedimento não era cumprido pela loja. Iniciado em 1851, o processo de falência do senhor Jacintho da Silva Lessa, seguia os ritos previstos no código, o que tornou longa a espera dos credores para receberem sua parte no rateio do fundo comercial. 10

\footnotetext{
${ }^{8}$ Contrato de sociedade ... 2 de agosto de 1832. Acervo Barão de Camargos, AHMI.

${ }^{9}$ Livros de notas, livro 204, folha 36v, 1854, AHмI.

${ }^{10}$ Quebra de casa comercial. vol. 2776, anos 1851-1854, AHмI.
} 
A necessidade de separação entre as contas do negócio e as contas dos indivíduos envolvidos é outro elemento que sugere maior precisão contabilística no cálculo de perdas e lucros. Para tanto, a definição das despesas se tornava mais comum e rigorosa nos contratos. A sociedade de tipo nome coletivo, celebrada entre Antônio de Souza Pinto Barros Cachapuz, Manoel Bento Malheiros e Joaquim Saturnino Vieira, em 1862, com fundo de mais de 62 contos (62 000 000), definia o que seria considerado despesa da casa comercial: "Artigo quarto.- São consideradas despesas gerais as seguintes: aluguéis da casa, sustento dos sócios, caixeiros e criados, salários, direitos, carretos”. Esse contrato foi, talvez, o mais rigoroso que encontramos, prevendo punição aos que "faltarem com a probidade" e proibindo a coexistência de negócios paralelos 11

Os sócios preocuparam-se, também, em fixar a retirada em 300000 réis mensais para cada um, o que evitava retiradas avulsas que fugissem ao controle. Isso sugere um nível mais elaborado de organização financeira e despersonalização dos negócios 12

Mesmo não havendo grandes firmas sociais em Ouro Preto, o crescimento do número de contratos e o aumento dos instrumentos de detalhamento contabilístico indicam um processo de maior formalização e despersonalização das finanças das casas comerciais, mesmo que de forma gradual. Segundo o Almanak administrativo, civil e industrial da provincia de Minas Gerais para o anno de 1864, das 23 lojas de fazendas listadas, cinco aparecerem como firmas sociais (Oliveira e Martins, 1864). Portanto, havia ainda um predomínio de negócios individuais, mas um crescimento das sociedades em relação às décadas anteriores.

Analisando a publicidade comercial, em jornais de diversas cidades mineiras, na segunda metade do século xix, Godoy (2004) identificou que cerca de um quarto dos anúncios já se referiam a essas sociedades comerciais, o que indicaria uma paulatina disseminação dos negócios associativos.

Mesmo com estas transformações, o comércio estabelecido continuou fortemente vinculado à figura da pessoa do proprietário, da qual o conhecimento popular e o prestígio convergiam para garantir idoneidade e confiança. Ainda segundo a pesquisa de Godoy (2004), mais de 90\% dos anúncios traziam o nome do proprietário da casa comercial, revelando a força social do nome do comerciante sobre o negócio.

No entanto, no final do século XIX, a capital da província seguia sendo a pioneira na difusão da impessoalidade e das estratégias de atração de consumidores, através dos anúncios. A pesquisa de Luiz A. Paixão (2002), revela que, em comparação com outros centros urbanos, Ouro Preto apresentava grande número de anúncios em que o endereço e nome do estabelecimento se sobrepunham ao nome do comerciante. Havia também uma maior exploração das marcas estrangeiras (americanas, francesas e inglesas) de produtos de perfumaria, tecidos, decoração e bebidas.

O processo de separação das pessoas e famílias dos capitais e da administração ocorria de cima para baixo, isto é, era quase exclusividade de alguns setores, localizados no topo hierarquia mercantil. A documentação consultada, sobretudo as escrituras cartoriais revelaram que no final da década de 1830 e na década de 1840, os maiores comerciantes de Ouro Preto, com trânsito regular no Rio de Janeiro, já experimentavam a prática associativa, embora existam poucas referências e contratos para a análise.

Os irmãos José Batista e Carlos de Assis Figueiredo, ambos já comerciantes, se associaram em 1845, com firma sob a razão social, José Batista de Figueiredo e Irmão. A partir de então passaram a registrar sob tal nome as hipotecas nas quais eram credores, por venda de gêneros no atacado

${ }^{11}$ Livros de notas, livro 212, folha 90, 1862, АнмI.

${ }^{12}$ Sobre a despersonalização e mecanização das práticas mercantis ver Yamey (1949, p. 100). 
ou empréstimos. Também na década de 1840, Tristão Francisco Pereira de Andrade estabeleceu sociedade de loja com seu filho, Manoel Pereira de Andrade e genro, Bernardo Lopes de Aguiar, a Andrade \& Aguiar 13

Outras experiências associativas ocorreram com aqueles que estabeleceram firma no Rio de Janeiro. Francisco de Paula Santos, foi sócio da Penna Santos \& Cia., fornecedora de fazendas para algumas lojas em Ouro Preto, casa que também descontava letras e agenciava a venda de apólices da dívida pública provincial mineira na Corte. Depois disso o mesmo comerciante abre a Santos \& Irmão, na Rua dos Pescadores, em sociedade com seu irmão mais novo, Joaquim José dos Santos Junior, que passara a intermediar os negócios financeiros do comendador no Rio. Também já mencionada, a Guimarães Lagoa \& Cia. operou na década de 1840 com o atacado de molhados, tendo Silvério Pereira da Silva Lagoa, como sócio ouro-pretano. 14

O enriquecimento com o comércio de escravos, de ouro e com a mineração subterrânea, principalmente com os investimentos ingleses, animou José Peixoto de Souza abrir uma grande casa comercial no Rio de Janeiro, em sociedade com os ingleses Salomon Bennaton e João Morgan Junior, em 1839. O contrato particular, registrado somente cinco anos depois no cartório de Ouro Preto, informava o fundo de 150 contos de réis, na sociedade de tipo coletivo. As 16 cláusulas são muito claras na separação dos negócios individuais daqueles da sociedade, na definição de despesas e divisão das tarefas. Ficava estabelecido que os dois ingleses promoveriam a casa no Rio de Janeiro, enquanto Peixoto de Souza, em Minas Gerais. Além disso, os primeiros tratariam com os correspondentes ou agentes da casa no interior. Não fica claro o objeto de comércio da casa, mas os indícios sugerem se tratar do comércio de fazendas, de escravos e talvez do ouro, utilizando o pagamento de comissão para correspondentes da casa, a começar pelo próprio José Peixoto de Souza 15

Apesar das iniciativas entre os mais ricos, os investimentos e métodos tradicionais ainda predominavam. Até meados do século XIX, o investimento em bens de raiz (imóveis) era o maior sinônimo de segurança e da garantia de perpetuação do patrimônio. Isto fez com que a corrida especulativa, gerada pelo comércio de ações, após o fim do tráfico e do Código Comercial, ${ }^{16}$ sofresse críticas e desconfiança. Interesses sociais mais conservadores, ligados à agricultura, foram fundamentais para o estabelecimento de legislação que limitava a criação e desenvolvimento das sociedades anônimas ou sociedade de capital, base da incipiente industrialização e do setor bancário 17

Ao operarem com diversos sócios que compravam ações, injetando capitais e sendo administradas por um mandatário, as sociedades anônimas permitiam a associação de capitais, para investimento em setores que necessitavam de grandes somas. Para o mercado nacional, os títulos

\footnotetext{
${ }^{13}$ Livros de notas, livro 200, folha 28v, AHMI.

${ }^{14}$ Livros de notas, diversas escrituras, AHMI.

${ }^{15}$ Livros de notas, livro 194 , folha $89 \mathrm{v}$, AHмI.

${ }^{16}$ Segundo Francisco Iglésias (1997), "o gosto pelas realizações materiais" ou "surto de iniciativas” foram marcas do período, em boa medida estimulado pela nova legislação regulamentadora e pela estabilidade política. É também chamada por Iglésias de a "Era Mauá", quando o empresário Irineu Evangelista de Souza (o Visconde de Mauá) domina o cenário de investimentos em diversos setores: indústria, transporte, bancos etc.

${ }^{17}$ Para um maior detalhamento da chamada Lei dos Entraves e a crise comercial da Corte de 1864, ver Levy (1994) e Guimarães (1997).
} 
das empresas passaram a corresponder por mais um ativo, que se somaria aos bens de raiz (imóveis urbanos e rurais), a escravos e apólices da dívida pública, no leque de opções de diversificação pela elite econômica.

Em Ouro Preto, as empresas de mineração, criadas com capitais associados ingleses e com participação de locais, foram as iniciativas de sociedade de capital mais presentes na região. A onda da mineração subterrânea se iniciou anos de 1820, tendo se estabelecido dezenas de empreendimentos na região. Somente as grandes empresas prosperaram, mas o ambiente dos negócios que giravam entorno delas era, sem dúvida, mais formalizado e profissional. Os dois maiores negociantes da cidade nos anos de 1840, Francisco de Paula Santos e José Peixoto de Souza, vendiam ou alugavam escravos para essas companhias, além de intermediar seus negócios com a comunidade mercantil local, como atesta nosso estudo anterior (Andrade, 2012). Depois de 1850, o próprio governo provincial passou a estimular a existência desse tipo de companhia para negócios que exigiam grandes somas de capitais, como fábricas de tecidos, Navegação e transportes (Andrade, 2013, p. 287).

\section{INVESTIMENTOS E INSTITUIÇÕES FINANCEIRAS}

Como temos visto, em Minas Gerais, a associação de capitais para formar firmas comerciais ou financeiras praticamente inexistiu na primeira metade do século XIX. Em 1846, o presidente da província instou negociantes e capitalistas da possiblidade de se criar um banco comercial com sede em Ouro Preto, mas não obteve sucesso 18

Talvez o que faltava na província não eram exatamente os capitais, mas a disposição dos grandes negociantes situados nos mais diversos pontos urbanos em torno de um projeto centralizado na capital. Aliás, nem mesmo havia uma associação que agremiasse os comerciantes da província, como a Associação Comercial da Bahia, a Sociedade dos Assinantes da Praça Comercial do Rio de Janeiro, ou a Associação Comercial do Rio Grande 19 A constituição de grandes fortunas mercantis e usurárias caracterizou-se pela concentração nas mãos de poucos homens, em pontos diversos da província. Eles eram ligados por suas redes de comércios e familiares, mais diretamente aos congêneres do Rio de Janeiro do que os do interior de Minas Gerais. Portanto, com pouquíssimas possibilidades de constituir um grupo de interesses.20

No entanto, a forma urbana de riqueza já estava muito presente nas principais cidades mineiras. Tanto em São João del Rei quanto em Ouro Preto, as fortunas de negociantes encarnavam esse perfil. Predominavam as dívidas ativas, decorrentes de empréstimos, imóveis urbanos e, no avançar da segunda metade do século xIx, apólices da dívida pública, ações e depósitos bancários. Nesse sentido, temos um processo de diversificação de investimentos, mantendo o caráter urbano, com traços de modernização, como ocorreu em Salvador, onde profissionais liberais, funcionários públicos, negociantes e rentistas representavam esse perfil (Mattoso, 1992).

Na passagem para a segunda metade do século XIX, houve um processo de descolamento da elite usurária-rentista-capitalista do conjunto de comerciantes lojistas estabelecidos, a quem, por tendência, restaria o pequeno crédito e instável negócio de compra e venda de mercadorias. O

\footnotetext{
${ }^{18}$ Correspondências, Presidência da Província, 1-3, cx 01, APM.

${ }^{19}$ A fundação da Associação Comercial do Rio Grande, em 1844, por exemplo, resulta nos esforços do grupo mercantil local em exercer seus interesses e influência. Berute (2011, p. 46).

${ }^{20}$ Sobre a atuação dos negociantes baianos, através da Associação Comercial da Bahia, por exemplo, e o conceito de grupo de interesse, ver Ridings (1973).
} 
grande crédito e os investimentos financeiros ficariam reservados aos primeiros, diferente da realidade das décadas anteriores, quando comerciantes lojistas tradicionais dominavam o setor financeiro (Andrade, 2013).

A análise dos inventários post-mortem, escrituras cartoriais, relatórios governamentais e do Banco do Brasil, permitiu-nos identificar que um pequeno grupo passara a investir parte de seus capitais em apólices da dívida pública, ações e depósitos bancários. O mais significativo é que na medida em que surgiam essas novas práticas, o vínculo com a loja, antes condição obrigatória para se envolver no negócio financeiro, vai desaparecendo (Andrade, 2013, pp. 303-310).

O Rio de Janeiro protagonizou a transformação do perfil de investimentos. Uma modernização que se operou muito mais no setor financeiro do que no produtivo rumo à industrialização, embora este último também estivesse em crescimento. Nesse caminho, Fragoso e Martins analisaram a transformação do empresariado do Rio de Janeiro:

Em princípios do século XIX o negociante de grosso trato não só controlava setores vitais do comércio - tráfico de escravos, importação-exportação e abastecimento- como também desempenhava o papel de usurário. Em suas mãos encontrava-se a liquidez do mercado. Já na segunda metade do oitocentos, esta elite econômica passou a concentrar suas atividades, principalmente na banca, deixando pouco a pouco o grande comércio entregue a outros segmentos do empresariado, e especializando-se nos empréstimos (Fragoso e Martins, 2003, p. 149).

Obviamente, não se trata de comparar os agentes estabelecidos em Ouro Preto com os grandes exportadores, comissários, industriais, banqueiros e rentistas do centro do império, mas identificar o sentido que orientava as mudanças das práticas dos agentes econômicos urbanos.

Estamos nos referindo aos chamados capitalistas, termo que não possui, até meados do século XIX, a mesma conotação de hoje. Capitalista era aquele que possuía dinheiro ou capital. Braudel (1996) explica o sentido que surge no século XviII: "Detentores de 'fortunas pecuniárias' é o sentido estrito que a palavra capitalista assume na segunda metade do século XviII, quando designa os possuidores de títulos públicos, de valores imobiliários ou de dinheiro líquido para investir” (p. 204).

Era com esse significado que a palavra aparecia em muitas referências do século xix, inclusive, na formação dos grandes empreendimentos bancários do Rio de Janeiro ${ }^{21} \mathrm{Na}$ Bahia, a designação capitalista era, como afirma Kátia Mattoso (1992), "comumente conferida a esses ex-comerciantes que permaneciam ligados aos negócios, fosse pela participação em outras sociedades comerciais, fosse investindo seu dinheiro em empreendimentos bancários ou industriais" (p. 643). Nas zonas cafeeiras de Lorena, em São Paulo, e de Paraíba do Sul, no Rio de Janeiro, grandes fazendeiros também diversificavam suas atividades, empregando excedentes em ações, apólices e no crédito hipotecário, tornando-se proprietários capitalistas (Marcondes, 1998).

Perseguindo a trajetória mercantil de muitos comerciantes de Ouro Preto, identificamos que uma parte deles passou de agente comercial-creditício para investidor capitalista. Foi possível identificar que $26.5 \%$ dos valores inventariados entre os negociantes e rentistas da cidade estavam

\footnotetext{
${ }^{21}$ Guimarães utiliza a seguinte definição: "No tocante à palavra capitalista, utilizamos o seu significado da época, ou seja, pessoa que tinha capital, dinheiro ou bens” (Guimarães, 2012, p. 20).
} 
revertidos em dívidas ativas e 37\%, em apólices, ações e depósitos bancários. Já entre os negociantes de São João del Rei, outra importante praça do interior mineiro, havia $47.11 \%$ em dívidas ativas e $26.43 \%$ em ações e apólices da dívida pública (Graça Filho, 2002).

Essa diferença se explicaria por dois motivos principais: o primeiro é o fato desses negociantes estarem na sede administrativa. Os sucessivos empréstimos provinciais, editais em que o governo emitia títulos, causavam maior atração aos negociantes-rentistas de Ouro Preto. O outro motivo é o fato de as jazidas auríferas já não despertarem grande euforia e a agropecuária da região central da província não ter os mesmos níveis de mercantilização do que a da comarca do Rio das Mortes, sediada em São João, por exemplo. Esses fatores unidos à própria limitação do comércio local fizeram com que alguns dos maiores negociantes ouro-pretanos migrassem seus capitais para ativos mais seguros.

Segundo Bárbara Levy (1994), os títulos públicos significavam um porto seguro, tanto para o produtor quanto para rentistas urbanos, pois produziam rendimentos certos e estiveram imunes às crises financeiras do século XIX.

No final da década de 1830 e na década de 1840, o governo provincial lançou mão de alguns editais para a venda de apólices da dívida pública, com o objetivo de financiar a construção da Estrada do Parahybuna, eixo importante que agilizaria a ligação entre Minas Gerais e o Rio de Janeiro. No início das operações, foi fundamental a atuação do maior negociante de Ouro Preto, Francisco de Paula Santos. A casa comercial da qual era sócio no Rio de Janeiro, a Pena Santos e Cia., realizava, sob comissão, as negociações e pagamentos de juros das apólices mineiras na capital do império. O valor nominal das apólices era de 500 000, mas o valor real era mais baixo, de modo a atrair os investidores que receberiam juros de $6 \%$ do valor nominal ${ }^{22}$

O próprio Paula Santos faria uma grande compra em sociedade com o também negociante José Peixoto de Souza no ano de 1841. Na oportunidade, 310 apólices (170 000 000) foram arrematadas por $62 \%$ de seu valor nominal (105 000 000), configurando um negócio vantajoso para a dupla, uma vez que nos anos posteriores, os valores pagos pelo governo para amortização das dívidas chegaram a 73 e $89 \%$ do valor nominal 23 Os dois maiores negociantes de Ouro Preto, na década de 1840, beneficiaram-se do fato de estarem sediados no centro político e administrativo da província para realizarem as transações que os transformaram em raros exemplos de capitalistas do interior do Brasil.

Em 1847, o comendador Paula Santos combinou com o presidente que participaria de mais um empréstimo provincial.

Sendo hoje o dia assinado para a apresentação das propostas sobre o empréstimo provincial, que se vai emitir, como foi anunciado em edital de 22 de outubro passado, tenho que propor à $\mathrm{V}$. Ex, que estou pronto a tomar todo o empréstimo, entretanto, como V. Ex. em conferência particular, concordou comigo em abrir uma espécie de praça entre os concorrentes capitalistas desta província, aguardo essa ocasião para oferecer as condições.

\footnotetext{
${ }^{22}$ Falla dirigida á Assembléa Legislativa Provincial de Minas-Geraes na sessão ordinaria do anno de 1840 pelo presidente da provincia (Veiga, 1840 en APM).

${ }^{23}$ Falla dirigida á Assembléa Legislativa Provincial de Minas-Geraes na abertura da sessão ordinaria do anno de 1842, pelo vice-presidente da provincia (Ferreira, 1842).
} 
Entretanto, se não houver concorrentes estou prompto para entrar em ajustes com o governo em qualquer dia que for designado ${ }^{24}$

O trânsito direto com o poder provincial é explicado pelos constantes socorros que o comendador Paula Santos, também deputado provincial, oferecia ao governo, em um período no qual poucos eram os negociantes e proprietários que confiavam parcelas de seus capitais aos fundos da dívida pública provincial.

Até a década de 1850, as exorbitantes taxas de juros cobradas no crédito local faziam desse setor tradicional de investimento o prioritário para quem dispunha de capitais. A partir do surgimento de instituições bancárias, o fim do tráfico, a consequente diminuição de escravos disponíveis para hipoteca e a concentração do alto crédito nas mãos de uns poucos capitalistas, é que os fundos públicos se tornariam uma opção mais generalizada na comunidade econômica local. ${ }^{25}$

Entre os negociantes-capitalistas da cidade de Ouro Preto difundiram-se os investimentos, principalmente, na dívida pública geral, que a partir da Guerra do Paraguai ganhou novo impulso. O governo precisava atrair capitais para o esforço de guerra e, por isso, passou a emitir títulos de curto prazo a $6 \%$ ao ano. A crise bancária de 1864 também estimulou uma verdadeira corrida aos títulos da dívida pública geral, na busca por investimentos mais seguros. Até mesmo os próprios bancos viraram grandes aplicadores nos títulos públicos, que tiveram um crescimento de emissão de 280\%, nas décadas de 1860 e 1870 (Levy, 1994). Seja por segurança diante das incertezas do mercado ou para diversificar investimentos, o fato é que os papeis do governo drenavam parte da acumulação da riqueza do país, restringindo ainda mais a disponibilidade de crédito para o setor produtivo.

A crise do escravismo também conduziu parte das riquezas de proprietários de terras e escravos para os títulos da dívida pública. Para Fragoso e Rios (1995), havia um sentido arcaico em tais escolhas. Esterilizar o patrimônio em ativos de baixo risco e não investir em novas formas de produção e relações de trabalho representaria o desejo da elite agrária de manter-se como senhores de terras e escravos, poupando maior parte do excedente, para se precaver das incertezas jurídicas da escravidão.

Em regiões como Ouro Preto, com baixos níveis de mercantilização das produções locais e com um comércio débil, essa opção de investimento veio a calhar, garantindo segurança patrimonial e uma espécie de aposentadoria. Se de um lado havia esse caráter conservador, por outro, tal movimento significou a diversificação e modernização de ativos, uma vez que o comércio lojista e o crédito pessoal perdiam em lucratividade devido à multiplicação da concorrência e dependência dos comerciantes das grandes firmas bancárias e importadoras.

Com seus robustos depósitos bancários, dezenas de apólices da dívida pública, domínio do crédito hipotecário e da direção de instituições financeiras, os capitalistas reforçavam o abismo que separava o comerciante de fazendas secas, outrora senhor da vida financeira urbana, dos grandes e mais lucrativos negócios 26

\footnotetext{
${ }^{24}$ Correspondências. Presidência da Província, 1-3, cx. 01, doc. 54, APM.

${ }^{25}$ Segundo Renato Marcondes (1998), após a expansão das Casas Bancárias do Rio de Janeiro sobre o mercado de crédito da cafeicultura do Vale do Paraíba, os capitalistas passaram a diversificar seus investimentos, apostando, majoritariamente em títulos da dívida pública.

${ }^{26}$ Pelo menos doze proprietários e negociantes de Ouro Preto, cujos bens foram inventariados nas décadas de 1860 e 1870, deixaram investimentos em apólices da dívida pública provincial ou geral. Inventários post-mortem. $1^{\circ}$ e $2^{\circ}$ ofícios, AHMI. Para visualizar nomes e valores, ver Andrade (2013).
} 
Outro importante agente investidor de Ouro Preto foi sua caixa econômica particular, que, desde 1838, passou a reunir o pecúlio da população local e investir em títulos da dívida pública e em outros ativos financeiros.

O rastreamento dos relatórios de presidente de província permite identificar que a criação da caixa econômica também corresponderia a um arranjo político. A casa comercial de Francisco de Paula Santos, sempre ele, seria a responsável pela compra das apólices e recebimento dos juros, com pagamento de comissões. Para a província, a vantagem clara seria a de ter mais uma fonte de financiamento das despesas públicas. Em outras regiões do império, as caixas econômicas também socorriam as finanças provinciais, canalizando as economias acumuladas das populações urbanas.

Pelo que consta nos relatórios das décadas de 1850 e 1860, o sucesso da Caixa de Ouro Preto fez com que pessoas de todas as classes passassem a poupar na instituição, que ganhou credibilidade com os bons dividendos e com a segurança dos investimentos administrados pela casa comercial de Francisco de Paula Santos. Os balanços anuais eram sempre positivos na diferença entradassaídas e o fundo crescia a cada relatório financeiro, que apresentava ainda a compra de ações do Banco do Brasil (Minas Gerais,1830-1930).

A caixa econômica particular de Ouro Preto, mesmo não sendo uma instituição de crédito e descontos, foi um importante instrumento de modernização e de profissionalização das práticas financeiras. Sua principal característica foi a identidade marcadamente ouro-pretana, mas com uma gestão financeira conectada ao mercado nacional. Possuía um padrão contabilístico interno bastante simplificado: armazenava as cadernetas dos depositantes, em que era registrado o movimento individual com entradas, saídas e dividendos 27

O prestígio e a prosperidade da caixa econômica indicam que a economia urbana de Ouro Preto passava por um gradual processo de financeirização e isso, logicamente, incluía as transformações vividas pelo capital e pelas práticas mercantis.

\section{A caixa FILIAL do BANCo do Brasil}

O processo de institucionalização da vida financeira brasileira estava em curso com as medidas legislativas do final da década de 1840, as quais deram confiança e tornaram mais previsíveis os investimentos. Uma reforma bancária de 1853 fundiu o Banco Comercial do Rio de Janeiro com o Banco do Brasil de Mauá. O objetivo do governo era conter a excessiva liquidez do mercado, centralizando e restringindo as emissões de moeda (Levy, 1994).

Inicialmente, a capilarização do banco se daria da seguinte forma: as caixas filiais do antigo Banco do Brasil de Mauá, em São Paulo e São Pedro do Rio Grande do Sul, foram incorporadas. Os Bancos Comerciais da Bahia, Pernambuco, Maranhã e Pará foram transformados em caixas filiais. As composições dos capitais de todas elas foram feitas com as disposições acionárias, constituídas anteriormente. Já a caixa filial do Banco do Brasil em Minas Gerais foi a única instituição a ser criada, o que completaria o círculo das mais ricas províncias alcançadas pelas operações de crédito e emissões do novo Banco do Brasil. Essa também foi a única a ser encampada com fundos próprios da matriz do Rio de Janeiro (Coleção das leis do Imperio do Brasil, 1854).

\footnotetext{
${ }^{27}$ Os relatórios provinciais que analisam contabilidade e a performance da caixa econômica particular de Ouro Preto foram apresentados em Andrade (2013, pp. 300-303).
} 
Existem fortes indícios da participação direta do nosso já conhecido comendador Francisco de Paula Santos nesse processo. O primeiro indício está no assíduo envolvimento de seu irmão mais novo, Joaquim José dos Santos Junior, sócio da Santos \& Irmãos, localizado na Rua dos Pescadores, no Rio de Janeiro, durante a formação do Banco do Brasil. Santos Junior foi presidente da Sociedade dos Assinantes da Praça do Rio de Janeiro ${ }^{28}$ entre 1854 e 1856, cargo que comandava a representação de demandas da classe mercantil carioca. Além disso, compôs a diretoria do Banco Comercial do Rio de Janeiro, em 1853, quando houve a referida fusão com o Banco Brasil de Mauá. A partir de então, fez parte da diretoria do novo Banco do Brasil até 1858 (Piñeiro, 2002).

O início da década de 1850 coincide com a ascensão política de Paula Santos. Depois de três mandatos como deputado da Assembleia Provincial, foi eleito para a assembleia geral, na qual permaneceria por seis mandatos. Em 1854, recebeu a Comenda da Ordem da Rosa. Um ano depois, fora eleito para diretoria do Banco do Brasil, permanecendo até 1863. O deputado participou assiduamente dos debates parlamentares sobre reformas no Banco do Brasil.

Em 1853, no calor das discussões da reforma, o comendador criticou os propositores do projeto, ao observar que "a classe dos homens práticos, a humilde classe dos homens práticos que eu tenho a honra de representar nesta casa, não está tomando parte nos debates" (Câmara dos Deputados, Brasil, 15 de junho de 1853). Suas intervenções sempre caminhavam no sentido de defender a disponibilidade de crédito e moeda sonante, fundamentais para o comércio e agricultura.

No período de constituição do estatuto da caixa filial de Ouro Preto, que serviu de base para as outras, seu irmão Joaquim José dos Santos Junior era um dos diretores da matriz. É importante observar que o período entre a aprovação do estatuto pelo Conselho de Estado e a efetiva abertura da caixa,1856, coincidiu com o ano em que, tanto Santos Junior quanto o comendador Paula Santos, faziam parte da diretoria, que era composta por quinze membros.

A decisão de instituir a caixa filial em Ouro Preto, apesar de São João del Rei ser a cidade mais rica e comercialmente mais movimentada da província, seguia o fato lógico de ser a capital de onde poderia emanar o crédito e a política monetária. Porém, também pode ter contado com a influência política de nomes como o comendador Paula Santos, o deputado conservador Manoel Teixeira de Souza, futuro Barão de Camargos, e o ouro-pretano, Honório Hermeto Carneiro Leão, o marquês do Paraná, chefe do gabinete da Conciliação e ministro da Fazenda.

A composição da diretoria da caixa filial sugere que a influência política dos negociantes, proprietários e rentistas de Ouro Preto também foi fundamental (ver tabela 1).

O presidente da instituição era o advogado, irmão mais novo e representante dos interesses de Francisco de Paula Santos, Marçal José dos Santos. Esse fato corrobora a tese da força dos irmãos Santos na diretoria da matriz. Os outros dois membros eram figuras conhecidas no comércio estabelecido e no crédito da cidade e, depois das nomeações, cresceriam ainda mais seus negócios e fortuna.

Francisco de Paula Santos e Manoel Teixeira de Souza parecem ter sido os intermediários da entrada de alguns membros da elite mercantil da cidade na cota acionária do Banco do Brasil, em seus primeiros anos de funcionamento.

\footnotetext{
${ }^{28}$ A Sociedade dos Assinantes da Praça do Rio de Janeiro foi criada em 1834 e presidida pelos maiores nomes do comércio, como Irineu Evangelista de Souza (visconde de Mauá), Barão do Ubá, visconde do Andaraí, Teophilo Benedito Otoni e outros. Em 1867, passou a se chamar Associação Comercial do Rio de Janeiro (Guimarães, 2012, p. 88).
} 


\section{TABELA 1. DIRETORIA DA CAIXA FILIAL DO BANCO DO BRASIL EM MINAS GERAIS}

\begin{tabular}{|c|c|c|c|}
\hline Cargo & Nome & Profissão & Atuação \\
\hline Presidente & Marçal José dos Santos & Advogado & $\begin{array}{l}\text { Irmão de Francisco de Paula } \\
\text { Santos; atuava no mercado } \\
\text { de crédito local. }\end{array}$ \\
\hline Diretor & $\begin{array}{l}\text { Francisco Teixeira } \\
\text { do Amaral }\end{array}$ & Advogado & $\begin{array}{l}\text { Atuava no mercado de crédito } \\
\text { local; escritório e residência } \\
\text { na Rua São José. }\end{array}$ \\
\hline Diretor & David Moretzsonh & Negociante & $\begin{array}{l}\text { Atacadista de fazendas secas } \\
\text { na Rua São José; atuava no } \\
\text { mercado de crédito local. }\end{array}$ \\
\hline Tesoureiroa & João Antônio Afonso & Negociante & $\begin{array}{l}\text { Negociante na Rua Direita; } \\
\text { foi o primeiro tesoureiro } \\
\text { da caixa econômica. }\end{array}$ \\
\hline
\end{tabular}

a $\mathrm{O}$ tesoureiro era um funcionário, não compunha a diretoria. Apresentou fiador, como garantia de 20000000 para exercer o cargo. Livros de notas, livro 208, folha 137v, AHMI.

Fonte: Oliveira e Martins (1864).

A destacada participação do comendador Paula Santos mostra, mais uma vez, a grande dimensão de seus negócios, a diversificação de seus investimentos e o enorme peso político, sinalizado pelos votos a que tinha direito. Sendo ele o principal mediador político deste setor econômico, provavelmente liderou todo o processo de modernização e reorientação de capitais da elite mercantil local. Já os membros da diretoria da caixa filial, gravitavam em torno do poder do comendador Paula Santos, ao mesmo tempo em que também se afirmavam como capitalistas e lideranças políticas (Andrade, 2013).

A compra de ações bancárias foi mais privilegiada pela elite local do que a de companhias de estradas de ferro, também em expansão no período. Ademais, como o tabela 2 demonstra, eram negociantes os primeiros investidores na casa bancária o que reforça a teses de terem sido eles, os principais investidores capitalistas de Ouro Preto.

Para além do organograma caseiro, a própria atuação da caixa filial, na primeira década de existência acabou por revelar que sua vocação prática era atuar, quase que exclusivamente, na capital da província. Relatórios de presidentes de província acusam a limitação do raio de atuação da agência, que atingia, no máximo, uma parcela do comércio de Ouro Preto e da vizinha Mariana.

Observa o digno presidente que: os saques que se fazem por esta Caixa são em geral por conta deste e do município de Mariana, não compreendendo eles todas a remessas que o commercio destas localidades faz para a praça do Rio de Janeiro, porquanto muitos interessados, para evitarem o pequeno dispêndio das comissões, procuram outras vias de remessa, arriscando o dinheiro por portadores, além do que empregam em ouro, cuja extracção avulta nos municípios vizinhos (Minas Gerais, 1859). 


\section{TABELA 2. MORADORES DE OURO PRETO ACIONISTAS DO BANCO DO BRASIL}

\begin{tabular}{llrrr}
\hline \multicolumn{1}{c}{ Acionista } & \multicolumn{1}{c}{ Profissão } & Ações & Votos & Valor investido \\
\hline Francisco de Paula Santos & Negociante & 694 & 34 & 138800000 \\
Manoel Teixeira de Souza & Proprietário & 303 & 15 & 60600000 \\
Marçal José dos Santos & Advogado & 60 & 3 & 12000000 \\
Manoel de Magalhães Gomes & Negociante & 35 & 1 & 7000000 \\
Francisco Teixeira do Amaral & Advogado & 30 & 1 & 6000000 \\
David Moretzsonh & Negociante & 25 & 1 & 5000000 \\
José Batista de Figueiredo & Negociante & 25 & 1 & 5000000 \\
Carlos de Assis Figueiredo & & & & \\
Antônio Luís de M. Musqueira & Negociante & 25 & 1 & 5000000 \\
\hline
\end{tabular}

Fonte: Relatório Accionistas do Banco do Brasil apresentado à na Assembléa Geral de 28 de julho de 1857 (documento cedido por Carlos Gabriel Guimarães).

Além da remessa direta de dinheiro para o Rio de Janeiro, os comerciantes mineiros estavam acostumados a se utilizarem de uma complexa rede, que incluía a transferência da dívida de um comerciante para outro, além do endosso de letras da terra. Rede essa que incluía descontos de letras em casas comerciais, que também eram fornecedoras de mercadorias, o que tornava possível o giro do comércio e a reposição dos estoques.

Dessa forma, não foi apenas o custo do pagamento de comissões à caixa filial que afastava alguns clientes, mas a manutenção de práticas mercantis tradicionais que garantiam a difícil sobrevivência do comerciante do interior. A institucionalização financeira não foi uma transformação que arrastou todos os atores mercantis como uma onda civilizadora. Ainda por décadas, a informalidade e as práticas de mercado não-institucionalizadas se manteriam, tanto no interior, quanto nas principais cidades.

As notas do Banco não tinham curso forçado na província, ou seja, a caixa filial nunca monopolizou a emissão. Mas a autoridade provincial defendia que o estabelecimento poderia ser muito útil para garantir a circulação e verificar a legalidade da diversidade do papel circulante.

No entanto, no final da década de 1850 e na década de 1860 o que se via eram casas comerciais que emitiam vales em substituição ao papel moeda. Os relatórios provinciais citavam, com preocupação, o caso da Almeida Reis \& Cia. de Diamantina, sobre a qual não havia qualquer controle e conhecimento dos fundos.

A polêmica com os vales comercias de Diamantina, região de um rico comércio e dinamizado pela extração dos diamantes, sugere que a política monetária emanada do centro estava longe, literalmente, de alcançar as praças interioranas do Brasil. Durante as décadas de formação do sistema bancário brasileiro, a solução para o crédito e o desconto continuo sendo local.

Afonso Graça Filho detectou o registro no Tribunal do Comércio da casa bancária, Santos \& Machado, de Diamantina, em 1863. Também na década de 1860, estreavam as casas: Jordão \& Gomes, José de Souza Lima \& Cia. e Mesquita Neves e Cia., todas em Juiz de Fora. A crescente produção cafeeira da região, o fortíssimo ramo do comércio e a agropecuária de abastecimento estiveram na base financeira destas casas bancárias. Em São João del Rei, algumas pode- 
rosas casas comerciais já operavam com o crédito e vales, desde a primeira metade do século XIX. Em 1860, Custódio de Almeida Magalhães, um dos maiores negociantes-capitalistas da província, fundou sua casa bancária na cidade (Graça Filho, 2002, pp. 65-67).

$\mathrm{O}$ atraso do desenvolvimento do sistema bancário regular em Minas Gerais talvez esteja ligado à dispersão de seus centros urbanos e comerciais, o que dificultava a reunião de capitais privados, mas também à proximidade de amplas regiões com o Rio de Janeiro e o fato de ter uma capital, que cumpria o papel de centro político, mas não econômico. Ademais, as casas bancárias ou casas de desconto, estabelecidas nesses centros mercantis parecem ter atendido ao chamado das demandas do mercado regional, o que corrobora a tese de que, de uma forma ou de outra, as práticas mercantis e financeiras paulatinamente estavam se modernizando.

\section{Conclusão}

É importante ressaltar que, mesmo Ouro Preto não sendo um grande centro financeiro, a trajetória de suas instituições e agentes mercantis permitiu-nos, em um análise micro focal, flagrar o processo de modernização e sofisticação de investimentos e práticas de mercado que se processavam no Brasil em meados século XIX.

Conhecedores das mais modernas formas de investimento, associações e escriturações mercantis, os maiores negociantes da cidade seguiam o ritmo da modernização, dentro das limitações da economia local. Por outro lado, tudo indica que a própria precariedade do comércio e da produção agrária ouro-pretana, acentuada na segunda metade do século XIx, também fez com que os investimentos rentistas mais seguros fossem buscados.

Por outro lado, velhas tradições e estruturas sociais, também permaneciam no mundo dos negócios. A pesquisa com inventários e escrituras cartoriais mostrou que muitos foram aqueles que mantiveram ou abriram negócio da loja fixa, por força das conjunturas econômicas ou mesmo pelo costume. Ademais, sendo uma sociedade escravista e fortemente hierarquizada, signos de prestígio e honra, além de práticas políticas clientelares, conviveram com o processo de racionalização das atividades econômicas, no campo e nas cidades.

Na segunda metade do século XIX, avançava não apenas o desenvolvimento de formas capitalistas de investimentos, mas também a integração mercantil do interior do Estado nacional brasileiro. Moldado nos tempos coloniais, agora o mercado interno movimentava mercadorias, mas também um conjunto de práticas que consubstanciavam a modernização e inserção do Brasil no capitalismo mundial.

\section{LISTA DE REFERÊNCIAS}

Andrade, L. B. (2012). Fortunas Subterrâneas: Negocias da capital da provincia de Minas Gerais e as companhias inglesas de mineração. Apresentado em Diamantina. Universidade Federal de Minas Gerais.

Andrade, L. B. (2013). Negócios capitais: Práticas mercantis, negociantes e elites urbanas na Imperial Cidade de Ouro Preto, c. 1822-c. 1864 (Tese de doutorado). Universidade Fedral do Rio de Janeiro, Rio de Janeiro.

Berute, G. S. (2011). Atividades mercantis do Rio Grande de São Pedro: Negócios, mercadorias e agentes mercantis (1808-1850) (Tese de doutorado, Universidade Federal do Rio Grande do Sul).

Brasil. (1850). Codigo commercial do imperio do Brasil. Rio de Janeiro. 
Brasil. (1854). Coleção das leis do Imperio do Brasil. Brasil: Conselho de Estado.

Brasil. Câmara dos Deputados. (1853). Anais da câmara dos deputados (Vol. 2). Recuperado de https://www.camara.leg.br

Braudel, F. (1996). Civilização material, economia e capitalismo: Os jogos das trocas. São Paulo: Martins Fontes.

Carvalho, V. (1888). Manual mercantil. Rio de Janeiro: s. e.

Chaves, C. M. G. (2006). Métodos e práticas do ensino mercantil profissionalizante no Império Luso-Brasileiro (1788-1822). VI Congresso Luso-Brasileiro de História da Educação, 43244334. Uberlândia.

Ferreira, H. (1842). Relatórios de Presidente de Provincia. Minas Gerais. Ouro Preto: Typhographya do Correio de Minas.

Fragoso, J. L. (1992). Homens de grossa aventura: Acumulação e hierarquia na praça mercantil do Rio de Janeiro, 1790-1830. Rio de Janeiro: Arquivo Nacional.

Fragoso, J. L. e Martins, M. F. (2003). Grandes negociantes e elite política nas últimas décadas da escravidão. 1850-1880. Em Ensaios sobre a escravidão (Vol. 1, pp. 143-165). Belo Horizonte: Universidade Federal de Minas Gerais.

Fragoso, J. L. e Rios, A. M. L. (1995). Um Empresário brasileiro no oitocentos. Em Resgate: Uma janela para o oitocentos (pp. 143-165). Rio de Janeiro: Topbooks.

Godoy, M. M. (2004). No país das minas de ouro a paisagem vertia engenhos de cana e casas de negócio (Tese de doutorado). Universidade de São Paulo, Rio de Janeiro.

Graça Filho, A. A. (2002). A princesa do oeste e o mito da decadência de Minas Gerais: São João del Rei, 1831-1888. São Paulo: Annablume.

Guimarães, C. G. (1997). Bancos, economia e poder no segundo Reinado: O caso da sociedade bancária Mauá Mac Gregore e Companhia (1854-1866) (Tese de doutorado). Universidade de São Paulo, São Paulo.

Guimarães, G. G. (2012). A presença inglesa nas finanças e no comércio no Brasil imperial: Os casos da Sociedade Bancária Mauá, MacGregor E̊ Cia. (1854-1866) e da firma inglesa Samuel Phillips E̊ Cia. (1808-1840). São Paulo: Fundação de Amparo à Pesquisa do Estado do Rio de Janeiro/Alameda.

Iglésias, F. (1997). Vida política. Em História geral da civilização brasileira. T. 2, vol. 3: O Brasil monárquico: Reacões e transacões (pp. 9-112). Rio de Janeiro: Bertrand Brasil.

Levy, M. B. (1994). A indústria do Rio de Janeiro através de suas sociedades anônimas: Esboços de história empresarial. Rio de Janeiro: Universidade Federal do Rio de Janeiro.

Marcondes, R. L. (1998). A arte de acumular na gestão da economia cafeeira: Formas de enriquecimento no Vale do Paraíba paulista durante o século XIX (Tese de doutorado). Universidade de São Paulo, São Paulo.

Mattos, I. R. (1990). O tempo saquarema: A formação do Estado Imperial. São Paulo: Hucitec.

Mattoso, K. M. (1992). Bahia, século XIx: uma provincia no Império. São Paulo: Nova Fronteira.

Minas Gerais. (1830). Provincial Presidential Reports: Minas Gerais. Recuperado de http://wwwapps.crl.edu/

Minas Gerais. (1859). Falla que á Assembléa Legislativa Provincial de Minas Gerais dirigio no acto da abertura da sessão ordinaria de 1859 o dr. Joaquim Delfino Ribeiro da Luz, 1.o vice-presidente da mesma provincia. Ouro Preto: Typographya Provincial.

Oliveira, J. M. e Martins, A. A. (1864). Almanak administrativo, civil e industrial da provincia de Minas Gerais para o anno de 1864. Ouro Preto: Typographya do Minas Gerais. 
Paixão, L. A. R. (2002). A publicidade e a formação da sociedade de consumo em Minas: Notas sobre a economia do consumo. Em X Seminário sobre a Economia Mineira, 23, 1-3. Diamantina, Universidade Federal de Minas Gerais.

Pedreira, J. L. M. V. (1995). Os homens de negócio da praça de Lisboa: De Pombal ao Vintismo (17551822). Diferenciação, reprodução e identificação de um grupo social (Tese de doutorado). Universidade Nova de Lisboa, Lisboa.

Pelaez, C. M. e Suzigan, W. (1981). História monetária do Brasil. Brasília: Editora Universidade de Brasília.

Piñeiro, T. L. (2002). Os simples comissários: Negociantes e politica no Brasil Império (Tese de doutorado). Universidade Federal Fluminense, Rio de Janeiro.

Revel, J. (1998). Microanálise e construção do social. Em Jogos de escalas: A experiencia da microanalise (pp. 15-38). Rio de Janeiro: Fundação Getulio Vargas.

Ridings, E. (1973). The merchant elite and the development of Brazil: The case of Bahia during the empire. Journal of Interamerican Studies and World Affairs, 15(3), 335-353. DOI: $10.2307 / 174971$

Rodarte, M., Paula, J. e Simões, R. (2004). Rede de cidades em Minas Gerais no século xix. História Econômica História de Empresas, 7(1), 7-45. DOI: 10.29182/hehe.v7il.167

Saba, R. N. P. F. (2010). As praças comerciais do Império e a aprovação do Código Comercial Brasileiro na Câmara dos Deputados. Angelus Novus, 77-96.

Veiga, B. J. da (1840). Relatórios de Presidente de Província. Minas Gerais. Ouro Preto: Typ. do Correio de Minas.

Weber, M. (1985). A gênese do capitalismo moderno; organização e comentários Jesse Souza; tradução Rainer Domschke. São Paulo: Ática.

Yamey, B. S. (1949). Scientific Bookkeepping and the rise of capitalism. The Economic History Review, 1(2-3), 99-113. DOI: 10.1111/j.1468-0289.1949.tb00108.x

Arquivos

AHMI Arquivo Histórico do Museu da Inconfidência.

APM Arquivo Público Mineiro. 